\title{
Angel Sermeño
}

\section{Sobre cultura y participación política}

\section{Introducción}

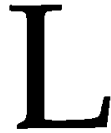

as categorías de cultura política y participación política ocupan en la actualidad una posición de primera importancia en el desarrollo conceptual de la ciencia política empírica. A partir de ellas se inició, en efecto, un enfoque de investigación original y novedoso que busca recuperar y comprender el papel de los valores, las actitudes y creencias de los individuos en la explicación de la naturaleza de su conducta política y, en general, de la configuración y dinámica de un determinado sistema político. Es decir, bajo está perspectiva de estudio se intenta, en rigor, establecer el tipo de relación existente entre, por una parte, las orientaciones subjetivas de una determinada población nacional y, por otra, el desempeño gubernamental social y económico manifestado por la misma. Cabe destacar, entonces, que la principal ventaja de tal enfoque de estudio consiste en abrir a la investigación politológica contemporánea una fértil veta de desarrollo en virtud de la cual se explica la praxis de los diversos actores políticos haciendo especial hincapié, como ya mencionamos, en sus motivaciones subjetivas 1 .

Existen, naturalmente, un buen número de definiciones del contenido de ambas categorías. Muchas de ellas son complementarias y algunas, por el contrario, contrapuestas. Ello debido al desarrollo de diversas teorías y problemas conceptuales y metodológicos surgidos al calor de la evolución de su estudio y que más adelante tendremos ocasión de exponer al menos en sus puntos fundamentales. Se trata, por tanto, de la admisión de diversas interpretaciones en torno al contenido específico de ambas categorías que difieren según los intereses del investigador y del marco de referencia teórica que se haya elegido. De ahí que en está introducción mostremos nada más una visión general e inclusiva del ámbito que abarcan tanto la cultura como la participación política. 
En términos generales, pues, se acepta por cultura política al conjunto de "creencias, valores y capacidades que son comunes al total de la población así como también a las tendencias especiales, modelos y patrones que sólo pueden encontrarse en sectores particulares de esta última (subcultura)"2. Como veremos más adelante, aparejados al concepto de cultura política se encuentran también los conceptos de socialización y secularización política. El primero dado que por su propia naturaleza engloba al proceso de introyección, sobre todo en los niños, de determinadas actitudes políticas y valores. El segundo, en cambio, debido a que se refiere a la modernización del sistema político mediante "el proceso por el cual los hombres acrecientan la capacidad racional, analítica y empírica de su acción política"3.

La cultura política se ocupa, ciertamente, de aquellos aspectos de la vida política menos tangibles y, por tanto, de difícil observación empírica. Forman parte de la cultura política de una sociedad, en tal sentido, los conocimientos, las orientaciones y las normas que los individuos poseen y comparten con relación al particular sistema político en el que viven 4 . De esta suerte, los conocimientos serían aquellas percepciones y convicciones del sujeto relativas a las instituciones, a las prácticas, a las fuerzas políticas, etc., que operan en un determinado contexto. Las orientaciones, en cambio, se referirían a las actitudes manifestadas hacia el ámbito de la política y que pueden ser tanto de aceptación (confianza, adhesión, tolerancia, etc.) como de rechazo (indiferencia, cinismo, rigidez, dogmatismo, etc.). Las normas, finalmente, estarían configuradas por aquellas reglas explícitas o implícitas - pero efectivamente operantesdestinadas a regir un determinado ordenamiento socio-político. Ejemplos de lo anterior serían: "el derecho y deber de los ciudadanos a participar en la vida política, la obligación de aceptar las decisiones de la mayoría, la inclusión o exclusión del recurso a formas violentas de acción, etc."5.

Existen, por lo demás, tres tipos fundamentales de cultura política. Se trata, en efecto, de una distinción ya clásica elaborada por los pioneros de la investigación sobre cultura política dentro del pensamiento politológico contemporáneo, a saber: G.A. Almond y S. Verba6. El criterio elegido por esos autores para articular dicha tipología se refiere al tipo de relación establecida entre el individuo y el sistema político al cual pertenece. Esos tipos de cultura política, en consecuencia, serían: cultura política parroquial, cultura política de subordinación y cultura política de participación.

La cultura política parroquial $\multimap$ premoderna- existiría esencialmente en sociedades simples y no diferenciadas en donde el incipiente desarrollo político no habría dado paso al surgimiento y consolidación de insti- 
tuciones políticas. Es decir, las funciones propias de ese tipo de instituciones estarían en manos de otras estructuras o instituciones ya sea de corte religioso, económico, etc. En rigor, por tanto, la cultura política parroquial carecería de orientaciones, creencias o motivaciones sobre fenómenos estrictamente políticos.

La cultura política de subordinación, a diferencia de la anterior, evidenciaría orientaciones de corte estrictamente político pero relacionadas más bien con aspectos parciales que con la totalidad del sistema político. En concreto, los sujetos poseedores de este tipo de cultura dirigirían su atención principalmente a aquellas estructuras o instituciones vinculadas con las "salidas" del sistema. Es decir, con la instituciones encargadas de hacer operativas las decisiones de corte administrativo tomadas dentro del sistema político. La participación de los individuos poseedores de este tipo de cultura suele ser, finalmente, de naturaleza "pasiva" y, en términos generales, serían comportamientos correspondientes a una cultura política propia de regímenes autoritarios.

Tenemos en último término la cultura política de participación. Obviamente, acá las orientaciones políticas de los individuos comprenden a la totalidad del sistema político. Esto es, abarcan los procesos de "entrada" (demandas y apoyos) como de "salida" (respuestas) de tal suerte que la participación del individuo suele ser activa en cada uno de esos momentos o aspectos. Las estructuras e instituciones políticas, por su parte, exigen y facilitan dicha participación para que el sistema funcione de manera eficiente. Tal cultura correspondería, en consecuencia, a una sociedad moderna con un tipo de régimen democrático.

Dicha tipología, por supuesto, posee un carácter más bien ideal. En la realidad, esos tipos difícilmente se expresan de manera pura. Esto es, existen, en concreto, culturas políticas (mixtas) más o menos participativas de modo tal que en ninguna de ellas se alcanza la participación completa o la apatía o anomia total. Ello acontece así debido a que en toda sociedad se revela, en diverso grado, una relación de congruencia o incongruencia entre la cultura política y las estructuras políticas. Es decir, para ilustrar lo anterior con un caso típico, suele ocurrir que en el terreno de la experiencia práctica aparecen individuos poseedores de una cultura política participativa que chocan frente a estructuras políticas propias de un régimen autoritario.

Ahora bien, la cultura política es un concepto congénere con el de participación política. Esto no significa otra cosa más que cultura y participación son categorías que por su íntima relación se remiten y complementan mutuamente una a la otra. Ello es así, como hemos adelantado, dado que la cultura política —conocimientos, orientaciones y normas- 
se expresa empíricamente a través del comportamiento y las actitudes de los individuos hacia el sistema político al que pertenecen. $Y$ estos comportamientos y actitudes en rigor constituyen el ámbito de manifestación propio de la participación política?.

Podemos entender, entonces, de una manera todavía muy englobante y general, por participación política a "aquel conjunto de actos y de actitudes dirigidos a influir de manera más o menos directa y más o menos legal sobre las decisiones de los detentadores del poder en el sistema político o en cada una de las organizaciones políticas, así como en su misma selección, con vistas a conservar o modificar la estructura (y por tanto los valores) del sistema de interés dominante" 8 .

De acuerdo con esta definición, en efecto, la esfera de la participación política abarca el extenso terreno de las actividades e intereses políticos de los individuos. El acto de votación, la militancia en el partido político, la participación en manifestaciones, la contribución dada a una cierta agrupación política, la discusión de sucesos políticos, la participación en un comicio o en una reunión sectorial, el apoyo dado a un determinado candidato en el curso de la campaña electoral, la presión ejercida sobre un dirigente político, la difusión de información política, etc., serían, en este sentido, ejemplos clásicos de participación.

La participación política se revela, en consecuencia, como un tipo de conducta social orientada a influir en el proceso político de toma de deliberación y decisión. Por supuesto, se presupone que el contexto de dicha participación, para que alcance su expresión y desarrollo óptimo, debe estar configurado por las estructuras de una sociedad moderna y con un régimen democrático. Por ello, en términos ideales, el sujeto de la participación deber ser un individuo libre e informado. Es decir, "un ciudadano atento a los desarrollos de la cosa pública, informado sobre los acontecimientos políticos, al corriente de las principales cuestiones (en debate), capaz de elegir entre las distintas alternativas propuestas por las fuerzas políticas y comprometido de manera directa o indirecta en formas de participación"9.

Como veremos más adelante, sin embargo, la realidad de la participación política suele ser muy diferente del esquema general anteriormente expuesto. Al menos, su ejercicio se vuelve más problemático de lo que a simple vista podría sospecharse. Dicho de otra manera, la plena participación suele ser, en la experiencia práctica, un privilegio de élites minoritarias mientras que grupos extensos de la sociedad quedan excluidos o su participación está limitada y restringida a formas "pasivas" de la misma. Ello acontece, incluso, en las sociedades auténticamente democráticas y se acentúa de manera todavía peor en aquellos regímenes no com- 
petitivos y autocráticos. Ya tendremos ocasión de estudiar las razones de este hecho. De momento conviene distinguir entre los distintos tipos de participación.

De acuerdo con G. Pasquino, la participación política adquiere tres tipos de modalidades básicas de expresión tomando como criterio de clasificación el grado de regulación y normatividad al que esté sometida dicha participación 10 . La primera modalidad, en efecto, estaría configurada a partir de las normas y los procedimientos legales vigentes dentro de un determinado ordenamiento socio-político (votar, firmar proposiciones de ley por iniciativa popular, etc.). Sería, en consecuencia, un tipo de participación reconocida por el status quo en turno y tendría como propósito fundamental integrar al individuo al sistema político11. La segunda modalidad, en cambio, representaría un tipo intermedio de participación por cuanto expresaría una relación del individuo con el sistema político no reconocida legalmente. Sin embargo, dadas las circunstancias, esa participación sería aceptada o tolerada si bien con importantes variantes y con amplios espacios de oscilación (adherirse a un boitcot, bloquear el tráfico, etc.). Finalmente, la tercera modalidad de participación sería aquella no sólo no reconocida por el marco formal del sistema político, sino que su manifestación y desempeño constituiría un abierto desafío a las bases mismas del sistema y de su organización. Ello se daría, por supuesto, con diferentes grados de ilegalidad o extralegalidad (negarse a pagar impuestos, revelarse violentamente contra el orden establecido, etc.).

Esbozado ya el amplio panorama general de ámbitos, teorías, estructuras y problemas que abarca el desarrollo de la cultura y la participación política procederemos, en los apartados siguientes, a profundizar en su respectivo estudio.

\section{Los estudios comparados de cultura política}

Los estudios modernos sobre cultura política coinciden con el florecimiento de la ciencia política empírica y se remontan hasta el inicio de la década de los sesenta con la aparición en Estados Unidos de la obra de Almond y Verba The civic culture (1963). No obstante, el concepto de cultura política de alguna manera siempre ha existido. Para Almond ese esfuerzo por explicar la conducta política y los lineamiento públicos a partir de los valores, emociones y creencias de los individuos se remonta, de hecho, hasta la misma antigüedad clásica griega12. El concepto de cultura política, en rigor, posee una amplia tradición.

Un rápido recuento de su incuestionable raíz clásica nos enseña como ya desde Platón se recalca la importancia del proceso de socialización en la introyección y cultivo de determinados valores y creencias políticas. 
Aristóteles, por su parte, se esmeró —n sus reflexiones politológicaspor relacionar de manera explícita la variable de estratificación social, por una parte, y a las variables del desempeño y la estructura política por la otra. Aristóteles, además, consideró a la participación política la base cultural para la mejor y más duradera forma de gobierno. Maquiavelo y Montesquieu, a su vez, recalcaron la importancia de los valores morales y religiosos para explicar el proceso de auge y decadencia del imperio romano. Rousseau, en cambio, aplicó los términos de moralidad, costumbre y opinión para identificar a la cultura política. Según Rousseau, esos términos configuraban una especie de ley más importante que la ley propiamente dicha ya que se trataba de una ley gravada en los corazones de los ciudadanos. Tocqueville, para citar un último ejemplo, hizo, como sabemos, uno de los análisis más agudos y complejos tanto de la democracia norteamericana como de los orígenes de la revolución francesa a partir de la comprensión y estudio de la cultura política.

En términos generales, el período comprendido por el siglo XIX y principios del XX representa, sin embargo, un retroceso en la comprensión y valorización de la cultura política. Esta pierde importancia o sencillamente desaparece de la reflexión teórica. La razón de ello estriba en que tanto para los pensadores liberales como para el marxismo, el estudio de la cultura política carecía de sentido. Para el pensador liberal, en efecto, el desarrollo político manifestado por la sociedad presuponía en sí mismo la existencia de un ciudadano participante, cívico y educado. El marxismo, curiosamente, compartía acríticamente - si bien a su manera- ese mismo prejuicio. Influido hondamente por el ideal de la ilustración, el marxismo creía en el advenimiento de una cultura de iluminación universal y una sociedad benefactora masiva, racional y crítica13.

Ahora bien, el surgimiento de la investigación moderna de la cultura política se explica, entre otras razones, por la enormidad e irracionalidad de las dos guerras mundiales experimentadas a lo largo de la primera mitad del siglo XX. Estos acontecimientos significaron, en la práctica, la quiebra y el fracaso del ideal del progreso lineal y ascendente de la especie humana proclamado con tanto entusiasmo por el proyecto de la ilustración. La variable de la cultura política, en consecuencia, recuperó su importancia explicativa y volvió a la escena de la reflexión politológica. Además, cabe destacar, el notable desarrollo de la sociología, psicología y antropología de la época que ofrecieron, por su parte, un invaluable estímulo y apoyo teórico-heurístico a la renovada comprensión de la cultura política14.

Para Almond, sin embargo, el más importante y decisivo apoyo para el desarrollo de la investigación moderna de la cultura política provino 
de la creación de la tecnología y metodología de la investigación por encuestas. Ello proporcionó, indudablemente, una base material sólida para el estudio empírico de las creencias, valores y actitudes políticas de los individuos. Es decir, sin el desarrollo de métodos de muestreo cada vez más exactos; sin la creciente complejidad de los métodos de entrevista; sin el desarrollo de técnicas para evaluación y elaboración de escalas; $\mathrm{y}$, finalmente, sin la creciente complejidad de los métodos para el análisis estadístico e inferencial, habría sido imposible abordar de manera científica la comprensión del fenómeno de la cultura política15.

El estudio moderno de la cultura política $-o$, si se prefiere, en perspectiva comparada - ha experimentado algo más de tres décadas de fructífero desarrollo. En ese período se pueden distinguir tres momentos evolutivos, a saber: el surgimiento de la teoría de la cultura política; la revisión crítica de la misma; y, en último término, el estado actual de la disciplina.

La idea fuerza de la teoría de la cultura política consiste, naturalmente, en la afirmación de la autonomía del ámbito de los valores, emociones y creencias políticas. Estas, efectivamente, no son el simple reflejo de la estructura social y política (marxismo) y tampoco son reducibles, a una concepción del individuo (individualismo metodológico) nacida del enfoque de la elección racional. Los factores subjetivos, en consecuencia, poseerían su propia normatividad para explicar algunos aspectos cruciales del comportamiento político de los individuos. La teoría de la cultura política, en su fase original, puede sintetizarse en opinión de Almond, en los puntos siguientes 16 :

1) Consta de un conjunto de orientaciones subjetivas en la política de una población nacional o en un subconjunto de una población nacional.

2) Tiene componentes cognitivos, afectivos y evaluativos. Incluye el conocimiento y las creencias sobre la realidad política, emociones con respecto a la política y compromisos con valores políticos.

3) El contenido de la cultura política es el resultado de la socialización de la niñez, educación, exposición a los medios de comunicación y experiencias adultas con el desempeño gubernamental, social y económico.

4) La cultura política afecta la estructura y el desempeño político y gubernamental, los limita, pero ciertamente no los determina. Los vectores causales entre cultura y estructura y desempeño son bidireccionales. 
Son cuatro, sin embargo, las perspectivas desde donde se ha criticado o revisado a la teoría de la cultura política. Todas ellas se concentran en discutir desde distintos enfoques la naturaleza y la dirección de la relación entre cultura y estructura social, así como también entre cultura y comportamiento político. Sus conclusiones -expresadas sintéticamenteson las siguientes.

La primera línea argumental reconoce que existe una relación bidireccional entre cultura y estructura como también entre estructura y comportamiento y desempeño político. No obstante, esta línea de reflexión, sostenida por autores como Brian Barry y Carole Pateman, cae a la postre en un determinismo, pues afirma con mayor énfasis que "la socialización política produce actitudes políticas que a su vez producen conductas políticas y subyacen a la estructura política"17. La crítica del pensamiento marxista también incurre en una revisión que privilegia el aspecto determinista de la relación examinada. Según tal planteamiento, los cambios de actitud de los agentes políticos producen cambios económicos y sociales de corte estructural. No obstante lo anterior, se reafirma que la lógica causal funciona desde las estructuras de clase hacia las actitudes, conductas y estructuras políticas. La tercera crítica rechaza, por su parte, la separación entre actitudes políticas y conducta. Acusa en tal sentido, a la teoría de la cultura política de limitarse a su aspecto psicológico e incurrir, por lo tanto, en una "subjetivización radical" del fenómeno en cuestión. La escuela de la elección racional, finalmente, propone que la estructura y la conducta política se explique mediante los cálculos del interés material a corto plazo de los actores políticos. Ello supone, naturalmente, el dejar de lado valores, normas, emociones y demás componentes cognitivos del individuo en la explicación de su conducta política. Variables como la historia o el contexto cultural, según la lógica anterior, no poseerían, en consecuencia, mayor valor explicativo.

Ahora bien, los estudios sobre cultura política contemporánea se han concentrado en tres áreas fundamentales de interés: 1) La cultura política de las sociedades industrializadas. 2) El papel de la cultura política en el desarrollo de sociedades comunistas y 3 ) el papel de la cultura política, económica y religiosa en la modernización de los países asiáticos. Un problema común a esas tres áreas de estudio se refiere al grado de estabilidad o cambio experimentado por la cultura política influido por las más diversas variables en esos distintos tipos de ordenamientos sociohistóricos. Es decir, una visión general de los resultados arrojados por las investigaciones en esos contextos históricos tan diversos ha permitido formarse una idea acerca de que tan estable es la cultura política y de cuáles son los factores que la transforman. 
Con relación a la cultura política de las sociedades industrializadas los estudios recopilados en The civic culture revisited (1980) revelan las tendencias siguientes: La cultura política es una variable sumamente plástica y volátil. En naciones como Estados Unidos e Inglaterra, en efecto, la cultura política ha sufrido una indudable erosión producto de un mal desempeño económico (crisis de efectividad del sistema) junto a un desprestigio de las instituciones políticas a raíz, por ejemplo, de fracasos en políticas de corte internacional (derrota en Vietnam) y a un escepticismo creciente en la capacidad del liderazgo político (crisis de integridad). En Alemania Occidental, en cambio, a lo largo de la década de los setenta y ochenta, la cultura política manifestó un notable fortalecimiento pasando de ser una cultura caracterizada por la pasividad y apoliticidad hacia una cultura cívica prodemocrática, politizada y participativa. Ello significa, para Almond, que "la cultura cívica declinante de los Estados Unidos e Inglaterra y la naciente cultura cívica en Alemania Occidental demuestran que la cultura política es una variable relativamente suave, influenciada mucho por la experiencia histórica y por la estructura y desempeño político y gubernamental"18. Cabe mencionar que junto a las variables de experiencia histórica y desempeño político gubernamental se encuentran otras variables significativas como los cambios generacionales y de socialización política, que han influido enormemente en la modificación de la cultura política de las sociedades avanzadas.

Los estudios sobre la evolución y desarrollo de las actitudes políticas en los países comunistas ha revelado y sugerido, sin embargo, que la cultura política también posee una extraordinaria resistencia al cambio19. Paradójicamente, en un contexto donde se realizaron esfuerzos transformadores conscientes, deliberados y potentes en materia de cambio cultural éste se registró pero en un grado relativamente insignificante. Sin duda alguna, ciertos aspectos fundamentales de esa cultura política han persistido, a pesar del cambio inducido, con bastante fuerza. Por ejemplo, los sentimientos nacionalistas y las identidades culturales y religiosas. En este sentido, Almond argumenta: "no obstante los esfuerzos sistemáticos de los movimientos comunistas por penetrar, manipular, organizar y adoctrinar durante décadas, no ha surgido el «hombre socialista» ni nada que se le parezca". De ahí que concluya: "si un control monopólico de los medios de comunicación, un monopolio o cuasi-monopolio de la organización, controles policíacos y similares no pueden transformar los valores y las actitudes, no tienen poder explicativo, entonces lo debe tener la cultura política y los procesos socializantes en que se apoya" 20.

La investigación sobre cultura política en sociedades asiáticas - particularmente aquellas que han mostrado un notable grado de modernización y desarrollo económico- ha dado paso, a su vez, al replanteamiento 
de la clásica hipótesis Weberiana que correlaciona las variables de cultura y religión con grado de desarrollo económico y político alcanzado. La cultura política, en esta perspectiva, se configura indiscutiblemente como una importante variable para explicar el cambio político. En términos esquemáticos pueden resumirse los resultados de dicha investigación sosteniendo que los valores del confusianismo - lealtad, educación, respeto a la autoridad, etc. - han contribuido al notable desarrollo económico de muchas de estas naciones tras la posguerra. En cambio, los valores del hinduismo y del islamismo han reforzado los esquemas políticos paternalistas y retrasado, en consecuencia, la modernización de muchas otras de esas sociedades - por ejemplo en el oriente medio21.

En conclusión, los estudios sobre cultura política a lo largo de las últimas dos décadas nos muestran que ella es una variable que "puede cambiar relativamente rápido pero también resiste muchos golpes sin cambiar demasiado"22. Dicho en otras palabras, existe un nivel superficial, el de los ánimos políticos de los individuos, en donde la cultura política es sumamente volátil. La confianza en los políticos y en las instituciones sociales y políticas, por ejemplo, suele ser fácilmente modificable en función de la eficacia y del desempeño de los líderes, funcionarios y agencias o instituciones. Existe, sin embargo, un nivel más profundo, el de las convicciones y valores políticos, en donde la cultura política se muestra muy resistente al cambio. Convicciones básicas tales como actitudes, identidades y valores vinculados o referidos a etnicidad, nacionalidad y religión - es decir, valores primordiales- parecen ser fuertemente inmodificables. De ahí que un régimen que funde su legitimidad en valores de esa naturaleza podrá considerarse sumamente estable. Cabe destacar, en definitiva, que existe importante evidencia empírica en virtud de la cual, sobre todo en las sociedades avanzadas, existe un desarrollo de la cultura política en dirección participativa y democrática23.

Ahora pasaremos al terreno en donde la cultura política expresa su influencia y manifestación empírica. Esto es, al terreno de la participación política. Aquí examinaremos, en consecuencia, cómo y bajo qué modalidades, los individuos sobre la base de sus creencias, valores, motivaciones e intereses actúan, normalmente en solidaridad con otros, para conservar o modificar la estructura -y por tanto los valores- del sistema político en el que viven.

\section{Los estudios comparados de participación política}

Los orígenes del fenómeno de la participación política, al igual que los de la cultura política, pueden rastrearse hasta la época de la Grecia o Roma clásica. Es decir, resulta evidente que ha existido, en un 
sentido laxo, participación política desde siempre; o, dicho con más precisión, desde el instante mismo en que se constituyeron las comunidades organizadas. En rigor, sin embargo, el fenómeno de la participación política adquiere su verdadera configuración y presencia solamente hasta la instauración de las formas modernas del Estado-nación en el mundo occidental.

L̇a participación política se encuentra, por ello, íntimamente vinculada con los procesos de democratización. Es decir, con la ejecución de medidas destinadas a propiciar una ampliación del número de participantes en las decisiones políticas y la reglamentación de la competencia por el poder. Esto supuso, por tanto, la adopción de medidas tales como la ampliación de la ciudadanía y del derecho al sufragio junto con la formulación y normatividad de derechos y deberes políticos. Como sabemos, numerosos estudios históricos nos ilustran como dicho proceso resultó sumamente largo, complejo, laborioso y conflictivo.

Para S. Rokkan, el proceso de ampliación de la participación política se articuló, justamente, a partir de la superación, por parte de aquellos individuos o grupos excluidos, de cuatro umbrales institucionales24. Estos umbrales son: a) el de la legitimación, a partir del cual se reconoce el derecho a la crítica y manifestación contra el régimen; b) el de la incorporación, que se identifica con la aceptación y el reconocimiento formal del derecho de participación en la elección de representantes; c) el de la representación, que supone, en efecto, la eliminación de obstáculos jurídicos para poder ser representado políticamente en los órganos respectivos; y, finalmente, e) el del poder ejecutivo a partir del cual se logra conquistar una influencia real del parlamento en la toma de decisión del ejecutivo.

Existe, en consecuencia, un nexo estrecho entre "los procesos de cambio social, reivindicaciones de derechos, expansión de la esfera de actividad del sector público y participación política. Si los individuos y grupos consiguen los recursos no sólo económicos, sino también jurídicos y políticos, y si el estado interviene en el sistema socio-económico, entonces son muy elevadas las probabilidades de que surjan fuertes impulsos a la participación política, así como estructuras adecuadas capaces de canalizarla y orientarla eficazmente" 25 .

La participación política, naturalmente, es un proceso con varias fases. Es decir, ella no se agota en la mera expresión de sus contenidos. Supone, antes que nada, un momento de politización previa y un momento posterior a la participación en donde se evalúa su receptividad y eficacia. En virtud del primer momento, el de la politización previa, es que los individuos adquieren conciencia de la importancia de la expre- 
sión de sus demandas, de la necesidad de construir canales de manifestación de la mismas, y, en definitiva, de la creación de estructuras organizativas - partidos, sindicatos, organizaciones civiles, etc.- destinadas a influir en el proceso de toma de decisión de la esfera política. El momento evaluativo, en cambio, es fundamental para consolidar ese proceso de politización de la manifestación de influencias y demandas. Es decir, al medir la efectividad alcanzada en la satisfacción de las demandas y necesidades expresadas resulta natural que se afirme y aumenten los umbrales y tipos de participación política.

Existen diversas formas de expresión de la participación política. De ellas, la más difundida y universal es la participación electoral Su importancia radica en que por su propia naturaleza constituye el momento culminante de un grupo de otras actividades $y$, a la vez, el punto de partida de otras posteriores. También, el acto del voto se ejerce de una manera u otra en casi la totalidad de sistemas políticos existentes. De ahí, por tanto, que no se pueda prescindir de su análisis para el estudio de la participación política en su conjunto. Adicionalmente a todo lo demás, no debe olvidarse que "donde la participación electoral no está eficazmente tutelada, todas las demás formas de participación política institucionalizada, pacífica, legal, resultan un tanto difíciles y precarias"26.

Una pregunta de importancia primordial, en consecuencia, en el estudio de la participación política es la que indaga ¿por qué votan las personas? o, dicho de otra manera, ¿quién vota? Es obvio que las respuestas a interrogantes de esa naturaleza buscan explicar cómo las personas "llegan a interesarse en la política, adquieren las informaciones necesarias y llegan a la convicción de que son eficaces" 27.

$\mathrm{Al}$ respecto, son dos las hipótesis principales manejadas por los especialistas. La primera coloca en el centro de la explicación al status socioeconómico. Tal hipótesis se fundamenta en una cantidad importante de evidencia empírica que tiende a demostrar que aquellas personas que se ubican en los puntos más altos de las escalas socioeconómicas votan y participan más. En contrapartida, la tendencia a la apatía y a bajos índices de participación se registra en los segmentos de personas socioeconómicamente más desfavorecidas. Ese mayor nivel de participación, en obvia y simple implicación lógica, correspondería al deseo de esos individuos de defender y mantener su posición privilegiada dentro de un determinado ordenamiento socioeconómico28.

La segunda hipótesis sostiene, sumándose en parte a la interpretación anterior, que la participación política es mayor "cuanto mayor -más intensa, más clara, más precisa- es la conciencia de clase». La importancia de ese enfoque consiste, según G. Pasquino, en que abre el camino 
para estudiar a la participación política más allá de las variables estrictamente individuales $y$, de ese modo, hacer espacio para comprender el papel de las variables de grupo, esto es, de las organizaciones destinadas a canalizar esa expresión grupal de las influencias y demandas. Recordemos que, en efecto, son las organizaciones el instrumento principal de canalización de la participación política. En palabras del propio Pasquino:

"Este es un punto en que se mezclan las variables que podemos definir como personales (interés, información, sentido de eficacia) con las variables de grupo. Estas se definen por lo general como: existencia de una comunidad relativamente estable, inserción de los individuos en redes organizativas, presencia de partidos que dirigen sus llamamientos y sus esfuerzos a la movilización de los sectores inferiores. La misma conciencia de clase (o de status) como variable explicativa del grado de participación política se define e interpreta mejor como la capacidad de las organizaciones de infundir solidaridad y de crear identidad en sectores sociales que participan de experiencias socio-económicas y culturales similares" 29 .

La pregunta de ¿por qué votan las personas? remite, por otra parte, a la consideración de la racionalidad última de la participación política. Es decir, lo que está en juego en esa interrogante es si la participación política es o no una realidad «ilusoria». Esa drástica objeción apunta al hecho incuestionable de que existen tipos de participación inducidos y manipulados desde el seno mismo de quienes controlan la marcha y conducción del sistema político. Se cuestiona acá, en consecuencia, el llamado aspecto instrumental de la participación, el cual contempla la persecución de un objetivo específico - la elección de un determinado candidato, por ejemplo- en cada acto de participación. Si se participa, entonces, a sabiendas de que ese objetivo concreto está perdido de antemano el sentido de la participación se pondría en severo entredicho. A tal objeción se responde, no obstante, demostrando que la participación no se limita a ese componente instrumental, sino que también posee un componente expresivo al cual se subordina muchas veces el instrumental. De acuerdo a esta clave de lectura se hace hincapié en que "se participa no sólo con el fin de tomar parte, sino en algunos casos especialmente para sentirse parte" 30 . Esto es para afirmar, por medio de la participación, la pertenencia a una clase social, a un grupo étnico, a una comunidad cultural, a una asociación profesional, etc.

En realidad, la racionalidad de la participación política se explica, nos dice $\mathrm{M}$. Olson, a partir de la articulación de tres elementos fundamentales consistentes en: a) las motivaciones de los individuos; b) la relación entre la acción individual y la acción de grupos; y, finalmente, c) la natu- 
raleza y la importancia de los beneficios y los incentivos individuales y colectivos 31 . Albert O. Hirschman, en este sentido, ha explorado con especial atención el elemento de las motivaciones individuales de la participación política aunque dentro de un contexto de la dinámica colectiva32.

El análisis de Hirschman arranca de una aguda e interesante observación. Las sociedades contemporáneas parecen, en efecto, estar predispuestas a oscilar entre unos períodos de intensa preocupación con los problemas públicos y otros, en cambio, de casi total concentración en las metas del mejoramiento individual y el bienestar privado. ¿Cómo se explica, entonces, dicha oscilación - tanto de los individuos como de los gruposentre la adopción de claros compromisos con la esfera de lo público y el retorno posterior al ámbito de lo privado? La clave explicativa, nos dice el autor, se encuentra en la búsqueda de la "felicidad". Esto es, tanto en la esfera de lo privado (representada por el mercado) como en la de lo público (representada por el Estado) los agentes de la acción colectiva persiguen alcanzar la felicidad. Sin embargo, ésta es imposible de lograr de ahí que se produzca la oscilación entre ambas esferas debido a la inherente decepción producida. En efecto, "la oscilación entre la persecución de sus propios intereses personales y el compromiso en actividades públicas, que parece darse no sólo en los individuos sino también en los sistemas políticos, se explica precisamente por la decepción de no lograr en ningún caso obtener la felicidad"33.

El impulso hacia la participación puede comprenderse mejor, en realidad, desde el análisis de los incentivos -comunes y generales- que la producen. Las organizaciones políticas, en efecto, recurren a incentivos de diversa naturaleza para movilizar de manera diferenciada a sus también diferenciados afiliados. Existen, de esta suerte, tres tipos de incentivos fundamentales, a saber: materiales, que se identifican con recompensas tangibles como asignaciones de dinero o cargos en la organización; de solidaridad, que tienen que ver con la identidad y el prestigio compartido por pertenecer a una determinada agrupación; y los «orientados al objetivo", que se refieren a objetivos de carácter ideal o ideológico como por ejemplo la transformación de las relaciones sociales o la creación de una sociedad justa. Lo importante de la distinción anterior es que ella permite entender ccmo "los distintos incentivos serán utilizados por las distintas organizaciones de manera selectiva, bien según sus disponibilidades o bien según el tipo de afiliados al que hay que motivar para que participen. El resultado es por lo tanto muy diferente no sólo de organización a organización y de individuo a individuo, sino también en el transcurso del tiempo"34. 
La diversidad de objetivos existentes nos permite comprender, en definitiva, el amplio rango de motivaciones que impulsan a los individuos a participar. También nos descubre la amplitud de los tipos distintos de organizaciones por medio de las cuales se canaliza la participación. De hecho, un mismo individuo u organización suelen sufrir importantes cambios en su comportamiento político en virtud, justamente, de la variación en sus intereses e incentivos. Resulta, en consecuencia, que la participación política se explica a partir de un complejo proceso psicológico y social que motiva a los propios individuos al compromiso político en sus diversas expresiones y que imprime diversos tipos de dinamismos a las organizaciones. La racionalidad de la participación política, como ya adelantamos, no debe, pues, tratar de agotarse a partir de la evaluación de uno sólo de sus elementos - por ejemplo la utilidad económica que puede proporcionar-, sino desde el conjunto complejo de esos elementos que la articulan.

Hemos visto hasta ahora como el análisis de la participación política conduce una y otra vez de manera inevitable hacia el estudio de las organizaciones. Y es que no sólo la participación política se explica en estrecha referencia a los grupos, sino que la realidad entera de la política moderna se comprende desde y por la existencia de las organizaciones. $\mathrm{Al}$ definirse, ciertamente, a la política moderna desde su rasgo de competencia entre grupos resulta que la participación política encuentra en los fenómenos de agregación política, grupos de interés y movimientos colectivos su lugar de manifestación más característico.

Una de las clasificaciones más influyentes de los tipos de grupos políticos existentes ha sido esbozada por Almond y Powell35. Desde el punto de vista de la articulación de intereses, es decir, de la manera como una comunidad política comunica al sistema sus preferencias y demandas, estos autores distinguen cuatro tipos de grupos de interés: anómicos, no asociativos, asociativos e institucionales.

Los grupos de interés anómicos corresponden a una etapa premoderna del desarrollo del sistema político. Se configuran a partir de intereses nuevos y sin canales adecuados de expresión. Los detentadores del poder político suelen, asimismo, ignorar y eludir reiteradamente las demandas externadas por esa vía. Los grupos de interés no asociativos surgen, por su parte, sobre la base de realidades tales como la estirpe, religión o parentela, lo que les da una cierta comunidad o semejanza de intereses. Ambas formas de articulación de intereses pueden manifestarse de manera espontánea y con un elevado grado de movilización y destrucción. Por supuesto, son formas de articulación de intereses que no han desaparecido del todo en la política moderna. 
Los grupos de interés institucionales, por su parte, son aquellos que se constituyen sobre organizaciones sociales dotadas de estabilidad y que comparten claros intereses comunes. Por ejemplo, organizaciones creadas sobre intereses religiosos, burocráticos, militares, etc., que basan su acción política sobre el tutelaje de prerrogativas y la defensa de sus privilegios. Los grupos de intereses asociativos, finalmente, son aquellos que han surgido al calor de los "procesos de modernización, diversificación y fragmentación social". Estos grupos se organizan para defender y promover sus intereses - sumamente plurales y diversos- a través de estructuras especializadas creadas para satisfacer ese fin. Ejemplos típicos de este tipo de grupos de interés lo constituyen las diferentes asociaciones profesionales de cualquier tipo, las asociaciones culturales, los sindicatos, etc.

A tales grupos corresponden, naturalmente, distintas modalidades de acción dentro de las cuales destaca la modalidad de presión. Tal es, en verdad, la forma clásica de acción de los grupos. La presión política, pues, se define como la capacidad organizativa y estratégica destinada deliberadamente a "influir sobre las opciones políticas y el personal que decidirá esas políticas y deberá llevarlas a cabo"36. La presión política, asimismo, se ejerce a través de numerosas variantes $y$, por supuesto, con diversos grados de éxito. De ahí que "cada grupo intentará maximizar sus oportunidades de éxito manejando los recursos a los que tiene más fácil acceso y utilizando los canales de comunicación y de presión sobre el poder político que le resulten más adecuado y más favorables, y, por último, cada grupo tratará de identificar con precisión el nivel político en que se toman las decisiones que le afectan y qué instancia toma las decisiones concretas" 37 .

Los factores que determinan el éxito o fracaso de un grupo de presión son, naturalmente, múltiples y complejos. De hecho, el grado de éxito conquistado depende de los tipos de recursos que dispone el grupo, la congruencia con las normas culturales del sistema político en el que se encuentra inserto, la representatividad, el dinero, la calidad y amplitud del conocimiento, la ubicación en el proceso productivo, etc. Una adecuada comprensión del éxito alcanzado por un determinado grupo de presión debe, en consecuencia, ponderar en su justa dimensión el aporte específico de cada uno de esos factores y evaluar como en un determinado contexto uno de ellos suele ser más determinante que los demás.

Las actividades de los grupos de presión, por lo demás, han sido objeto de una doble reflexión crítica. La primera de ellas, que podemos identificar como la crítica neoconservadora, afirma que es falso que los grupos de presión constituyan la mejor modalidad de organización de 
las sociedades democráticas. En contrapartida, argumenta que estos grupos y su actividad constituyen, de hecho, un "diafragma interpuesto entre los ciudadanos y los gobernantes, como un obstáculo a la realización del bien común y una ventaja para la realización de intereses precisamente particulares" 38 . Dicha critica coloca su atención a la lógica de la organización de grupos muy limitados y destinados a perseguir fines limitados y específicos pero con un poder de convocatoria y organización para la acción colectiva desproporcionada. Ello redunda, en definitiva, en la afirmación de "un problema de rigidez social y de división desproporcionada de las amplias coaliciones distributivas" 39 .

La segunda critica proviene de vertientes de reflexión neoprogresistas y surge del estudio de las relaciones entre los grupos de intermediación y los órganos del aparato estatal en la dictaminación y ejecución de las políticas públicas. Como nos explica Pasquino:

"El problema que se plantea, en concreto, es si el intercambio de consenso por políticas públicas entre el sindicato y los organismos estatales es más fácil, duradero y eficaz con un sindicato monolítico, verticalista, centralizado, o bien si son los sindicatos con estructuras y procesos internos democráticos capaces de soportar, absorber y canalizar las tensiones derivadas de la consecución y la realización de acuerdos neocorporativos. En general, la respuesta parece ser ambivalente. Aquellos sindicatos que son más centralizados y verticalistas llegan con más facilidad a arreglos y acuerdos neocorporativos. Por otra parte, son los sindicatos que ofrecen mayores posibilidades de participación interna, y que por tanto pueden ser más representativos, los que recogen mejor los desafíos que se derivan de los acuerdos neocorporativos y los que se enfrentan con mayor eficacia a sus consecuencias" 40 .

No cabe duda, en definitiva, que a pesar de las bien fundadas y racionales críticas anteriores, la participación política más influyente es aquella que nace y se explica desde dentro de las organizaciones. Ello no excluye, sin embargo, que en las condiciones del mundo contemporáneo aparezcan otras formas de participación política nada ortodoxas. Por ejemplo, los diversos tipos de participación que se articulan a partir de los movimientos colectivos.

A diferencia de los grupos de presión, en efecto, los movimientos colectivos o sociales son aquellos que se caracterizan por "la falta de estructuras estables, por la presencia de programas sectoriales y por la composición generalmente definida por características particulares (sexo, edad, intereses diversos, actividad social, etc.). Tales movimientos tienen frecuentemente también una duración limitada en el tiempo y el espacio 
uniéndose a momentos particulares de la vida sociopolítica y a ambientes territoriales determinados" 41 . La importancia de estos movimientos es, por supuesto, muy grande en términos de influir y determinar no raras veces la dinámica del sistema político y social. Tales movimientos han surgido, normalmente, para "pedir la revisión de las bases políticas tradicionales o la consideración de nuevos problemas" 42 . De ahí que comúnmente se les considere movimientos de protesta social antisistema. Acá, finalmente, el terreno de la investigación empírica tiene todavía un amplio horizonte que cubrir. Así, en efecto, son objeto de investigación el complejo cúmulo de problemas relacionados con "las interrelaciones entre las energías desplegadas por los movimientos, sus demandas y las respuestas del sistema y los actores individuales" 43 .

\section{Conclusión}

A modo de conclusión, ofrecemos en las líneas siguientes un breve balance de los desafíos y perspectivas de los estudios de cultura política y participación política en el presente. Lo primero que hay que decir al respecto es, naturalmente, que el desarrollo de las investigaciones sobre cultura y participación política en los últimos treinta años han posibilitado la maduración y consolidación de ambos enfoques de estudio en el seno de la ciencia política empírica. Tanto la cultura como la participación política, en efecto, han delimitado rigurosamente su área de reflexión, han perfeccionado sus estrategias de investigación $y$, por supuesto, sus aportes al conjunto de la ciencia política empírica han dado lugar a una persistente y prolífica polémica en la disciplina. De ahí que la labor de investigación ofrezca numerosas e interesantes perspectivas de estudio. Acá mencionaremos solamente algunas de las más prometedoras.

El estudio de la cultura política enfrenta en la actualidad el desafío de ampliar su campo de investigación al ámbito completo, es decir, hacia los diversos aspectos y estructuras, del sistema político. En todo sistema político, no dice Almond, pueden distinguirse tres niveles, a saber: el del sistema propiamente dicho, el de sus procedimientos y el de sus lineamientos. Por tanto, la cultura política debe ser reflexionada justamente desde los problemas abiertos por esta triple distinción y así construir una teoría de la cultura de los sistemas, de los procesos y de los lineamientos44.

Bajo tal perspectiva de análisis, la cultura política del sistema sería el conjunto de conocimientos, emociones y evaluaciones tanto de los líderes y funcionarios como del régimen (estructura institucional) y, también, de la nación. La estructura política de los procesos, por su parte, se expresaría igualmente a través de los conocimientos, emociones y evaluaciones 
aunque ahora sería de los miembros del sistema políticos hacia sí mismos en tanto que actores políticos y hacia los demás actores políticos incluyendo otros grupos, por ejemplo, partidos o grupos de interés y élites gubernamentales y políticas. Finalmente, la cultura política de los lineamientos serían los conocimientos, emociones y evaluaciones, ahora de los miembros del sistema político hacia los productos del sistema45.

Disgregar el estudio de la cultura política a partir de los componentes del sistema reporta, nos dice Almond, importantes ventajas para la investigación. Ante todo permite explorar la estructura lógica e interactiva de la cultura política, además de que tiene la ventaja de apoyarse firmemente en la estructura y desempeño del sistema político. Como nos dice el propio Almond:

"Es evidente que estos tres niveles de cultura política están íntimamente relacionados. Desde un punto de vista simplista, queda claro que la insatisfacción con los lineamientos producidos probablemente ocasione insatisfacción con las autoridades que los formularon. La insatisfacción con el proceso político probablemente de insatisfacción con el régimen. La insatisfacción sostenida con los lineamientos puede, en cierto tipo de sistema político, conducir a un cambio de autoridades y la insatisfacción prolongada con el proceso político puede llevar a un cambio estructural o de régimen. El mal desempeño a nivel proceso o lineamientos en los países que tienen varios componentes éticos, puede a la larga socavar la legitimidad nacional y dar lugar a movimientos de secesión o autonomía ... En cambio, los lineamientos y procesos satisfactorios pueden fortalecer la legitimidad de las autoridades, los regímenes y las naciones. Existe algo parecido a un proceso de acumulación y reducción de capital en esta interacción entre proceso y lineamientos políticos con la legitimidad del sistema" 46 .

De ahí que paradójicamente la investigación sobre participación política concentre buena parte de su atención y recursos en comprender y resolver el problema de la "crisis de participación" que se constata en las sociedades contemporáneas. He aquí, quizás, uno de los principales desafíos actuales en el estudio de la participación política.

En el campo de la paricipación política, por su parte, los desafíos abiertos a la investigación son, como ya habíamos intuido, extraordinariamente amplios y complejos. Ello es debido, ante todo, a que los individuos poseen hoy una posibilidad mucho mayor que antes para participar. Es decir, su participación política puede ser hoy mucho más significativa y superar, incluso, los umbrales de la simple participación electoral. Es empíricamente constatable, en efecto, la existencia de un creci- 
miento y una difusión de los instrumentos de participación política. También que han aumentado considerablemente las formas de participación heterodoxas, no convencionales. Sin embargo, todo ello "no supone en modo alguno que se hayan borrado las tradicionales diferencias en términos de nivel de participación o que la participación lleve necesariamente a una mayor igualdad" 47 .

La crisis de participación, por supuesto, es un problema complejo. Admite en su seno al menos tres tipos de modalidades48. Corresponde, en primer lugar, al fenómeno de la apatía política. En efecto, una de las características de las sociedades modernas (de masas) es un cierto desinterés difuso por la política. La causa de ello se afirma consiste en, por un lado, la tecnificación y burocratización del proceso de toma de decisiones $y$, por otro, a la correspondiente despolitización que supone esa burocratización del poder. En segundo lugar, por crisis de participación se entiende al fenómeno de la participación distorsionada o deformada. Sería éste un tipo de participación propia de una democracia manipulada y fundamentada, por ejemplo, en un dominio sobre. los medios masivos de comunicación lo que permitiría, a quien detenta el poder, la manipulación del consenso. Finalmente, la crisis de participación también adquiere la forma de una participación ficticia. Es decir, se trata de aquella participación que no produce los efectos que de ella se esperan. En otras palabras, que es ineficaz. El individuo que participa no logra a pesar de sus esfuerzos influir o alcanzar un papel efectivo en el proceso de toma de decisiones.

La crisis de participación es, pues, un problema que asume manifestaciones complejas y múltiples. Encontrar soluciones adecuadas, por tanto, supone, como decíamos, un importante desafío que cuestiona, más allá de la participación política en sí misma, al centro neurálgico de la teoría democrática contemporánea.

Notas

1. Para estudiar el funcionamiento de los sistemas políticos pueden colocarse como pivotes fundamentales de reflexión el comportamiento empírico de los procesos, las instituciones y\o los actores políticos. La cultura política vendría, en esta perspectiva, a enriquecer la comprensión del comportamiento de los actores a partir, justamente, de sus motivaciones subjetivas. De hecho, el concepto de cultura hace referencia a «la dimensión psicológica del sistema político». En cambio, la participación política nos permitiría analizar y conocer el comportamiento de las instituciones y asociaciones políticas. Naturalmente, ello desde la perspectiva del individuo más que de la institución en sí misma. 
2. G.A. Almond y G.B. Powell. Política comparada: una concepción evolutiva, Buenos Aires, Paidos, 1972.

3. op. cit.

4. G. Sani. "Cultura política", en N. Bobbio y N. Matteucci (eds.), Diccionario de política, México, Siglo XXI, 1985.

5. op. cit p. 470.

6. G.A. Almond y S. Verba. The civic culture, Princeton, N.J, Princeton Universite Press, 1963. (Debe mencionarse, asimismo, a G.B. Powell).

7. "La actividad política -en efecto- se caracteriza por relaciones que se producen de formas, modos, con frecuencia e intensidades distintas entre individuos, grupos, asociaciones e instituciones. Estas relaciones se clasifican y analizan fundamentalmente dentro de la categoría de participación política". Cfr. G. Pasquino. "Participación política, grupos y movimientos", en G. Pasquino, S. Bartolini, M. Cotta, et. al., Manual de ciencia política, Madrid, Alianza Universidad Textos, 1991, cap. 5, pp. 179-215.

8. op. cit. p. 180.

9. G. Sani. "Participación política", en N. Bobbio y ... Diccionario de ... op. cit. p. 1181.

10. G. Pasquino... op. cit.

11. Aquí cabría recordar que "las estructuras de participación más importantes están vínculadas en las sociedades democráticas a los mecanismos de competición entre fuerzas políticas y generalmente están institucionalizadas en los procedimientos del sistema que afectan la renovación de los cargos públicos". Cfr. G. Sani, "Participación ... op. cit. p. 1182.

12. G. Almond. A Discipline divided. Schools and secta in political sciencia, Newbury Park, Sage, 1990, cap. 5, "The study of polítical culture", pp. 139-156.

13. Explica Almond: "Marx indudablemente estaba dentro de la tradición de la iluminación, excepto que dispuso las variables teóricas de manera diferente y veía el proceso histórico en términos diálecticos en vez de incrementales. En vez de que el avance intelectual empuje el progreso político-moral y material en secuencia benigna, el avance capitalista produce tres subculturas políticas: una clase capitalista cada vez más explotadora y concentrada, una clase trabajadora explotada, adoctrinada y dominada, y una organización iluminada de revolucionarios. El resultado final es una cultura de iluminación universal y una sociedad de bienestar masiva, racional y creativa". Cfr. op. cit. p. 142.

14. "Hubo tres componentes intelectuales -indica Almond- que alimentaron la investigación de la cultura política: la tradición sociológica de Weber, Durkeim, Mannhein, Parsons y otros, la tradición socio-psicológicas de Graham Wallas, Walter Lippman, Willian McDougall, E.L.Thorndike, Paul Lazarsfeld y otros y la tradición psicoantropológica que se originó al principio de Freud e incluyó a Theodore Adorno, Max Horkeimer, Else FraenkelBrunswik, Nevitt Sanford, Ruth Benedict, Margaret Mead, Harold Lasswell, Alex Inkeles, Daniel Levinson y muchos otros". Cfr. op. cit. p. 143.

15. "La invención de la investigación por encuestas - señala Aldmond- es comparable a la invención del microscopio, haciendo posible una resolución muy aumentada y precisa de los datos biológicos por una parte y de los datos 
políticos, psicológicos y sociales por otra". Cfr. op. cit.

16. op. cit. pp. 144-145.

17. op. cit. p. 145.

18. op. cit. p. 147.

19. Almond reconoce y advierte, sin embargo, que las conclusiones sobre la evolución de la cultura política en las sociedade comunistas no cuentan con el debido apoyo empírico. Las conclusiones extraidas, en consecuencia, deben interpretarse con la cautela exigida por el caso. "Por desgracia, dice Almond, hay pocas encuestas adecuadas disponibles sobre la cultura política de los países comunistas...". Cfr. op. cit. p. 149.

20. op. cit.

21. "En vez de ver la ética de las religiones como condición necesaria para el crecimiento económico, Winston Davis afirma que puede influir en el crecimiento económico, ya sea facilitándolo o tolerándolo y obstruyendo el desarrollo de actitudes y valores conducentes a la disciplina y el desempeño". Cfr. op. cit. p. 150.

22. op. cit. p. 151.

23. "La teoría político-cultural de hoy — sintetiza Almond- no es el conjunto de ideas orientado a familia, niñes e «inconsciente» de los cuarenta sino más bien una teoría con énfasis en actitudes y expectativas a nivel cognoscitivo inluenciadas por la estructura y desempeño del sistema político y la economía. Pero si es en gran parte fluida y plástica, existen sin embargo componentes persistentes y estables tales como convicciones políticas básicas y apego a valores así como vínculos primordiales que afectan y restringen nuestra conducta política y nuestros lineamientos públicos". Cfr. op. cit. p. 153.

24. S. Rokkan. Citizens, electión, parties, Oslo, Universitetsforlaget, 1970. Citado por G. Pasquino. "Participación política... op. cit. p. 182.

25. G. Pasquino. "Participación política... op. cit. p. 183.

26. op. cit. p. 186.

27. op. cit.

28. Las personas con mayor interés en la participación política, de acuerdo a dicha hipótesis, serían aquellas ubicadas en el vértice de la escala de la estratificación social. Esto es, "aquellas personas y grupos que disponen de un nivel de renta elevado, tienen un buen grado de instrucción, desempenan un trabajo no manual, controlan su propio tiempo, pertenecen a sectores sociales, linguísticos, religiosos y étnicos dominantes". Cfr. op. cit. p. 187.

29. op. cit. p. 188.

30. op. cit. p. 191.

31. M. Olson., The Logic of collective action, Cambridge, Mass., Harvard University Press, 1965. Citado por G. Pasquino. "Participación ... op. cit. p. 192.

32. A. O. Hirschman., Interés privado y acción pública, México, Fondo de Cultura Económica, 1986.

33. G. Pasquino. "Participación... op. cit.

34. op. cit p. 193. 
35. G. Almond y... Política comparada... op. cit.

36. G. Pasquino. "Participación... op. cit. p. 199.

37. op. cit. p. 200.

38. op. cit. P. 202.

39. op. cit.

40. op. cit. p. 203.

41. U. Cerroni. Política. Método, teorías, procesos, sujetos, instituciones y categorías, México, Siglo XXI, 1993, p. 91.

42. op. cit. p. 92.

43. G. Pasquino. "Participación... op. cit. p. 211.

44. G. Almond. "The study of political culture... op. cit. p. 154.

45. op. cit. p. 155.

46. op. cit.

47. G. Pasquino. "Participación... op. cit. p. 213.

48. N. Bobbio., "La crisis de participación", en Nexos, México, año XII, vol 12, $\mathrm{N}^{\mathrm{o}}$ 137, mayo de 1989, pp. 51-54. 